\title{
Assessment of the surface and structure of elements produced in additive manufacturing technology after chemical treatment
}

\author{
Dawid $\mathrm{M}$ arciniak ${ }^{1, *}$ \\ 1UTP University of Science and Technology, Department of M anufacturing Techniques, AI. prof. S. \\ Kaliskiego 7, 85-796 Bydgoszcz, Poland
}

\begin{abstract}
Samples made of A BS material were produced on devices from three different manufacturers: Stratasys, V elleman, $3 \mathrm{~N}$ ovatica. The quality of the printed surface was improved by vaporization with acetone vapours. Roughness measurements were performed, which proved the improvement of the surface after vaporization. The structure of the produced samples was also tested using a computer microtomography. It has been shown that excessive exposure to the solvent significantly changes the geometrical dimensions of models exposed to the vaporization process.
\end{abstract}

\section{Introduction}

Additive manufacturing technologies, as opposed to conventional technologies for producing elements from polymer materials, are characterized by high surface roughness. This phenomenon is caused by the layered deposition of plasticized material [1]. The side walls of the produced model have grooves where the layers meet, which is caused by the geometry of the nozzle outlet [2]. These grooves disqualify elements produced additively from some applications, e.g. despite printing from a material certified for contact with food, food remains in the cracks, where bacteria and fungi multiply with success. Manufacturers of additive manufacturing machines strive for the best possible quality of models, placing less emphasis on the mechanical properties of these products [3]. There are many methods of improving the quality of printed surfaces. We can distinguish chemical methods such as vaporization [4], where the material is treated by vapours of solvent, or short-term solvent baths and coatings. Mechanical methods include: machining, polishing and sandblasting of printed models [5-7]. Vaporization with acetone is one of the best methods of improving the quality of printed surfaces made of acrylonitrile butadiene styrene (ABS) [8]. The surface of the element treated with this method resembles the moulded part obtained with the injection technology [9]. The outer layer of the printed model becomes more smooth as the ABS is dissolved by acetone [10]. The biggest disadvantage of additive technologies is the occurrence of technological voids. These are areas of discontinuity in the model caused by the method of overlapping single paths of material [11].

The aim of this work is to evaluate the printed surface after acetone vaporization treatment and to evaluate the structure of printed samples, as well as the influence of acetone vapours on technological voids.

\section{Methodology}

The test samples were made in accordance with PN EN ISO 527, shape 5a. The material used to produce the samples was a $1.68 \mathrm{~mm}$ ABS P430 filament from Stratasys (Israel). The samples were made on 3 devices for rapid prototyping: Dimension Elite by Stratasys (Israel), Vertex K8400 by Velleman (Belgium) and Gate 1.0 by 3Novatica (Poland). The roughness

* Corresponding author: dawid.marciniak@utp.edu.pl 
was measured on a Mahr Surf profilographometer (Germany). The geometry of the samples was measured with a MarCal 16EWR caliper from Mahr (Germany). The microtomographic examination was performed using the SkyScan 1272 from Bruker (Belgium). The acetone vaporization process was carried out on a stand designed for the needs of the research [4]. The parameters of the printing process are presented in Table 1. The nozzle diameter was a variable during the production process. Roughness measurement and geometry measurement were performed before vaporization and 48 hours after the acetone vaporization process. The time of conditioning the samples in acetone vapors was variable and amounted to $10 \mathrm{~s}, 20 \mathrm{~s}$ and $30 \mathrm{~s}$.

Table 1. Parameters of 3D printing proces.

\begin{tabular}{|c|c|c|c|}
\hline Parameters & Dimension Elite & Gate 1.0 & Vertex K8400 \\
\hline N ozzle diameter $[\mathrm{mm}]$ & 0,35 & 0,50 & 0,4 \\
\hline Temperature of printing $\left[{ }^{\circ} \mathrm{C}\right]$ & 275 & 275 & 275 \\
\hline Temperature of heated bed $\left[{ }^{\circ} \mathrm{C}\right]$ & 75 (heated chamber) & 75 & 75 \\
\hline Speed of printing $[\mathrm{mm} / \mathrm{s}]$ & unknown & 40 & 40 \\
\hline Layer thickness $[\mathrm{mm}]$ & 0,254 & 0,254 & 0,254 \\
\hline
\end{tabular}

\section{Results}

The samples were prepared at three different devices differ in initial average value of roughness. The best result was obtained for the Dimension Elite device, the roughness was lower by about $50 \%$ compared to the other devices (Fig. 1). The reason for such a result was the use of a tightly closed working chamber in the Dimension Elite printer, in which the process temperature was kept constant $-75^{\circ} \mathrm{C}$, it limited the irregular cooling of individual printed layers, and thus the internal stress in the produced model.

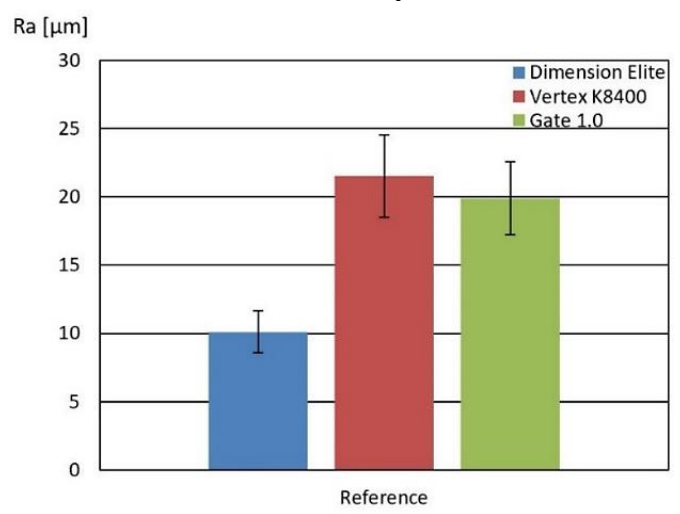

Fig. 1. Average roughness of samples before acetone vaporization.

Figure 2 shows the average roughness measurement results for different sample exposure times to acetone vapours. The greatest improvement in surface quality was observed for the longest duration of acetone exposure to a printed sample - $30 \mathrm{~s}$. For Dimension Elite, the reduction in Ra value was $5050 \%$, for the Vertex K8400 printer this value decreased by $3583 \%$ and for Gate 1.0 the decrease in the average Ra value was $1809 \%$. 


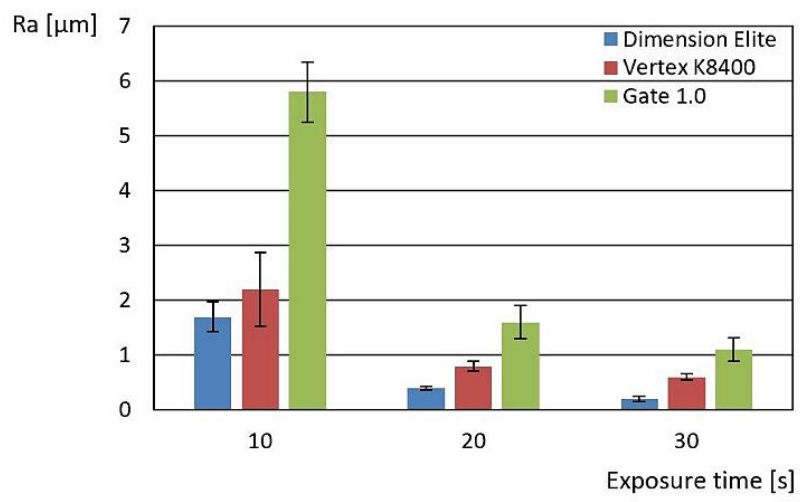

Fig. 2. Average roughness results for samples after acetone vaporization.

The structure of the samples was examined using the non-destructive method, i.e. computed tomography. Figure 3 shows examples of cross-sections of reference samples in the research section. The reference samples were not treated with acetone. It was observed that depending on the diameter of the nozzle in a given device, the size of technological voids formed in the process of 3D printing (black fields in figure 4-6) differed. Technological voids arise as a result of forced movement of the print head caused by the control software. The head's nozzle has the shape of a circle, which makes it impossible to print the perfect angles (there are always radii) generated by the model cutting software. In addition, the stream of plastic leaving the nozzle flows to the sides, which causes less discontinuity in the model. In figure $3 \mathrm{c}$ ), a large deformation of the test sample can be observed, which was caused by the design of the device, which allowed for uneven cooling of the applied layers.

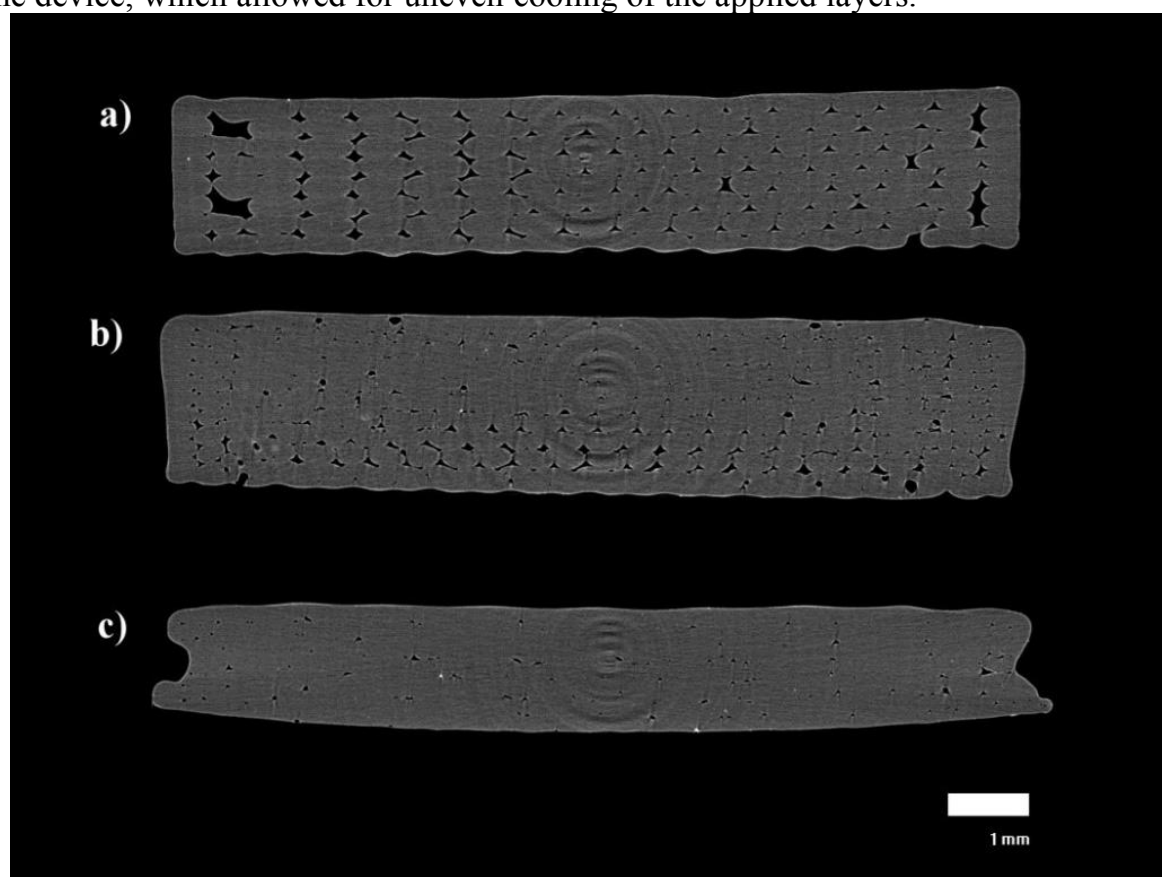

Fig. 3. Examples of cross-sections of the samples printed before vaporization of acetone vapours: a) Dimension Elite, b) Vertex K8400, c) Gate 1.0. Black areas inside the sample - technological voids. 
On figures 4-6 are examples of cross-sections of the samples subjected to the process of acetone vaporization. As the time of exposure to acetone vapours increases, a decrease in technological voids can be observed. The best results were observed for samples produced on the Dimension Elite.

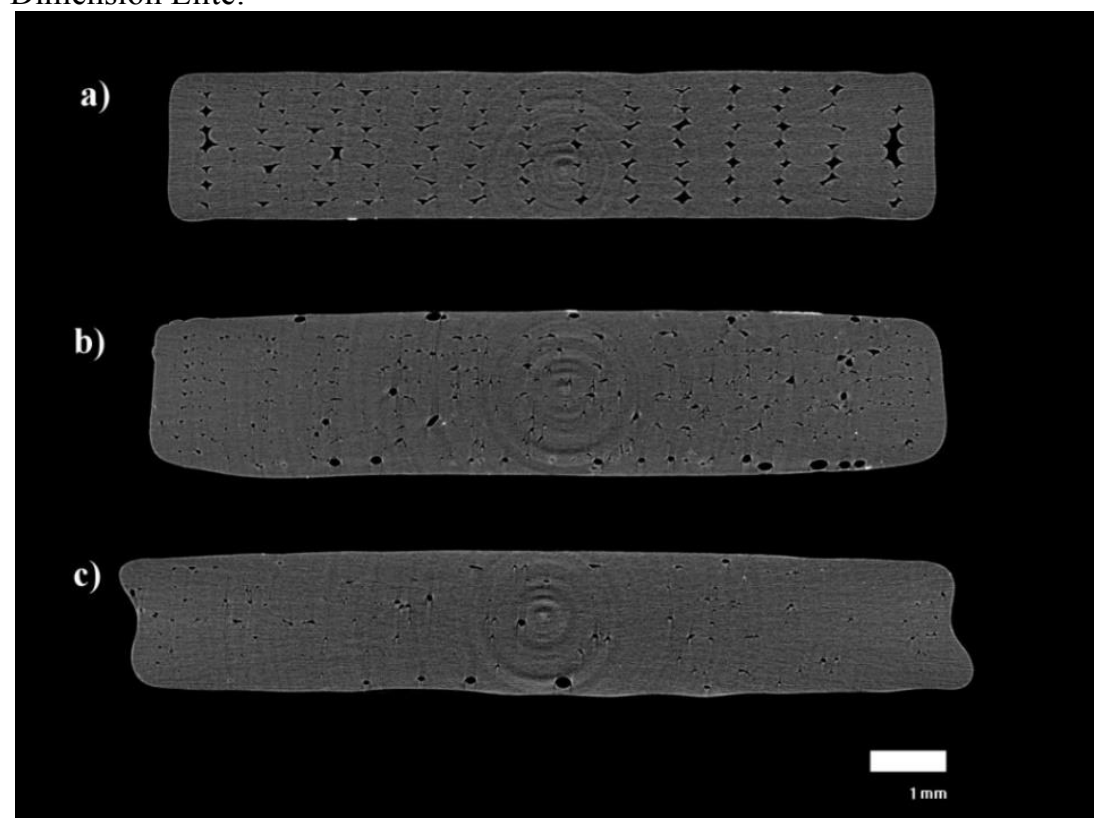

Fig. 4. Examples of cross-sections of the samples printed after vaporization with acetone vapours during $10 \mathrm{~s}$ : a) Dimension Elite, b) Vertex K8400, c) Gate 1.0. Black areas inside the sample technological voids.

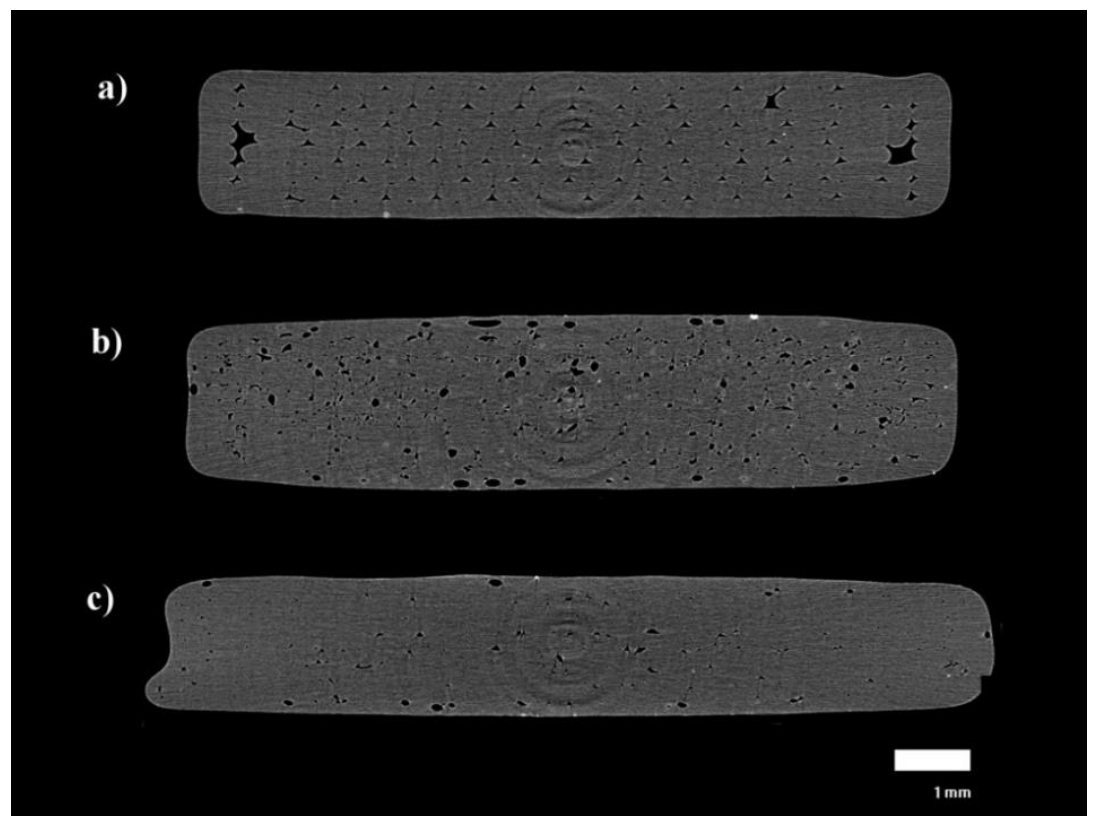

Fig. 5. Examples of cross-sections of the samples printed after vaporization with acetone vapours during 20 s: a) Dimension Elite, b) Vertex K8400, c) Gate 1.0. Black areas inside the sample technological voids. 


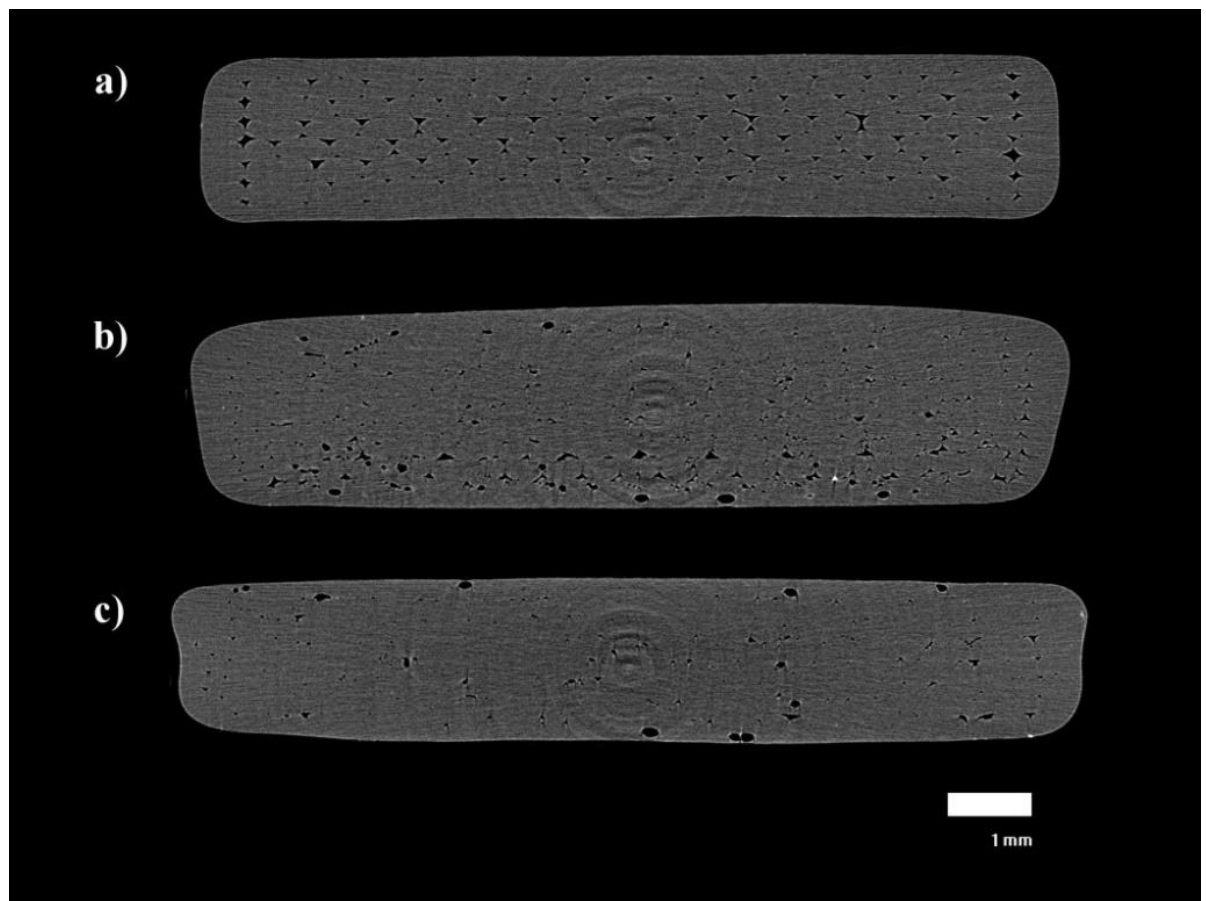

Fig. 6. Examples of cross-sections of the samples printed after vaporization with acetone vapours during 30 s: a) Dimension Elite, b) Vertex K8400, c) Gate 1.0. Black areas inside the sample technological voids.

An analysis of the void spaces present in the test samples was also performed using the CTAn software (Bruker). The analysis allowed to confirm the reduction of technological voids with the increase of exposure time to solvent vapours. The results are presented in Table 2. The highest percentage of voids during and after vaporization can be observed for samples made on the Dimension Elite device. On the other hand, the smallest average void size was observed for samples made on the Vertex K8400 device.

Table 2. Percentage of voids and average pore size for samples printed by Dimensional Elite, Vertex K 8400 and Gate 1.0 printers.

\begin{tabular}{|c|c|c|c|c|}
\hline \multirow{2}{*}{ Indicator } & $\begin{array}{c}\text { Exposure } \\
\text { time [s] }\end{array}$ & $\begin{array}{c}\text { Dimension } \\
\text { Elite }\end{array}$ & $\begin{array}{c}\text { Vertex } \\
\mathbf{K 8 4 0 0}\end{array}$ & $\begin{array}{c}\text { Gate } \\
\mathbf{1 . 0}\end{array}$ \\
\hline \multirow{3}{*}{$\begin{array}{c}\text { Technological } \\
\text { voids [\%] }\end{array}$} & 0 & 1,40 & 1,29 & 0,56 \\
\cline { 2 - 5 } & 10 & 1,10 & 1,08 & 0,50 \\
\cline { 2 - 5 } & 20 & 0,94 & 0,75 & 0,46 \\
\hline \multirow{3}{*}{$\begin{array}{c}\text { A verage pore size } \\
\left.\text { [mm }{ }^{2}\right]\end{array}$} & 30 & 0,89 & 0,62 & 0,42 \\
\cline { 2 - 5 } & 10 & 0,33 & 0,46 & 0,86 \\
\cline { 2 - 5 } & 20 & 0,29 & 0,39 & 0,42 \\
\cline { 2 - 5 } & 30 & 0,25 & 0,18 & 0,30 \\
\hline
\end{tabular}

The geometric measurement of the samples was also made (Table 3), which shows that the length of the samples $(\mathrm{L})$ after acetone vaporization slightly changed. The average width of the samples in the measuring section (B) decreased by $3 \%, 2.9 \%$ and $4.6 \%$ for Dimension Elite, V ertex $\mathrm{K} 8400$ and $\mathrm{G}$ ate 1.0, respectively. A verage sample height $(\mathrm{H})$ decreased by $3.3 \%, 4.3 \%$, and $6.3 \%$ for Dimension Elite, V ertex K 8400 and $\mathrm{G}$ ate 1.0 , respectively. 
Table 3. A verage geometric measurements of samples before and after vaporization.

\begin{tabular}{|c|c|c|c|c|c|c|c|c|c|}
\hline Device & \multicolumn{2}{|c|}{ Dimension Elite } & \multicolumn{3}{c|}{ Vertex K8400 } & \multicolumn{3}{c|}{ Gate 1.0 } \\
\hline $\begin{array}{c}\text { Exposure } \\
\text { time [s] }\end{array}$ & $\begin{array}{c}\mathrm{L} \\
{[\mathrm{mm}]}\end{array}$ & $\begin{array}{c}\mathrm{B} \\
{[\mathrm{mm}]}\end{array}$ & $\begin{array}{c}\mathrm{H} \\
{[\mathrm{mm}]}\end{array}$ & $\begin{array}{c}\mathrm{L} \\
{[\mathrm{mm}]}\end{array}$ & $\begin{array}{c}\mathrm{B} \\
{[\mathrm{mm}]}\end{array}$ & $\begin{array}{c}\mathrm{H} \\
{[\mathrm{mm}]}\end{array}$ & $\begin{array}{c}\mathrm{L} \\
{[\mathrm{mm}]}\end{array}$ & $\begin{array}{c}\mathrm{B} \\
{[\mathrm{mm}]}\end{array}$ & $\begin{array}{c}\mathrm{H} \\
{[\mathrm{mm}]}\end{array}$ \\
\hline \multirow{3}{*}{$\mathbf{0}$} & 75,01 & 4,01 & 2,16 & 74,87 & 4,49 & 2,44 & 75,58 & 4,73 & 2,01 \\
& \pm & \pm & \pm & \pm & \pm & \pm & \pm & \pm & \pm \\
& 0,02 & 0,03 & 0,02 & 0,15 & 0,07 & 0,06 & 0,21 & 0,15 & 0,07 \\
\hline \multirow{3}{*}{$\mathbf{1 0}$} & 74,95 & 3,94 & 2,14 & 74,68 & 4,44 & 2,36 & 75,19 & 4,64 & 1,95 \\
& \pm & \pm & \pm & \pm & \pm & \pm & \pm & \pm & \pm \\
& 0,05 & 0,03 & 0,04 & 0,12 & 0,04 & 0,02 & 0,30 & 0,17 & 0,17 \\
\hline \multirow{2}{*}{$\mathbf{2 0}$} & 74,94 & 3,92 & 2,13 & 74,61 & 4,39 & 2,35 & 75,14 & 4,57 & 1,90 \\
& \pm & \pm & \pm & \pm & \pm & \pm & \pm & \pm & \pm \\
& 0,03 & 0,04 & 0,05 & 0,11 & 0,08 & 0,03 & 0,25 & 0,19 & 0,13 \\
\hline \multirow{3}{*}{$\mathbf{3 0}$} & 74,89 & 3,89 & 2,09 & 74,58 & 4,36 & 2,34 & 75,11 & 4,52 & 1,89 \\
& \pm & \pm & \pm & \pm & \pm & \pm & \pm & \pm & \pm \\
& 0,04 & 0,01 & 0,04 & 0,08 & 0,04 & 0,02 & 0,14 & 0,13 & 0,14 \\
\hline
\end{tabular}

\section{Conclusions}

Three different printers of different design and accuracy were used in the study. The best turned out to be Dimension Elite - a professional printer, characterized by the best surface quality and the highest accuracy. The second was the Vertex K8400, which had the smallest nozzle diameter which keeps the quality high. Gate 1.0 with $0.5 \mathrm{~mm}$ nozzle was the least accurate.

Acetone vaporization is one of the best methods to improve the quality of ABS models. Thanks to acetone, the surface quality of the samples was at a high level.

Acetone dissolves ABS, so surface quality can be improved with a short exposure time. Be careful that the exposure time was not too long, because it can permanently damage the printed model.

The big difference in roughness results is caused by application of different printers and their working conditions, despite similar settings. The samples were printed on the Dimension elite, were sealed in a heating chamber throughout the process and had a constant temperature. The samples printed on the Vertex K8400 printer were exposed to blasts of air, which resulted in faster cooling of individual layers of the model. Samples prepared for the Gate 1.0 in addition to air blasts were exposed to higher vibrations because of the movements of the heated table moving in the $\mathrm{Y}$-axis

Regardless of the machine used, acetone for vaporization, provides a high surface quality that exceeds the quality standards of the best printers, also is the cheapest option for improving surface quality.

\section{References}

1. P. Czyżewski, M. Bieliński, D. Sykutera, M. Jurek, M. Gronowski, Ł. Ryl, H. Hoppe, Rapid Prototyping Journal, V ol. 24, Iss. 9, pp. 1447-1454, (2018)

2. P. Czyżewski, M. Falkiewicz, S. Siutkowski, Badanie technologiczności drukowania obiektów przestrzennych $w$ technologii FDM (Fused Deposition Modeling), 18 Nationwide Conference: Recirculation Vol. 19 Iss: 2, pp.118 - 125 in Machine Construction, Bydgoszcz, Poland, (2014)

3. D. Michta, B. Kaczmarska, W. Gierulski, A. Szmidt, Uniwersalność druku $3 d w$ technologii fdm. Conference materials.

4. D. M arciniak, P. Szewczykowski, P. Czyżewski, D. Sykutera, M, Bieliński, Polimery, Vol.63, No. 11-12, pp. 785-790, (2018) 
5. S.-H. A hn, M. M ontero, D. Odell, S. Roundy, P. Wright, Rapid Prototyping Journal, 2002, V ol. 8 Iss: 4, pp. 248 - 257, (2002)

6. R. Sanatgar, C. Campagne, Nierstrasz, A pplied Surface Science, V olume 403, pp. 551563, (2017)

7. A. A rmillotta, Rapid Prototyping Journal 12(1), pp.35-41 (2006)

8. R. Singh, S. Singh, I. Singh, F. Fabbrocino, F. Fraternali, Composites Part B: Engineering, 111, (2017)

9. M. Dawoud, I. Taha, S. Ebeid, J ournal of M anufacturing Processes, 21, (2016)

10. S. Pietanza, D. Sorgente, G. Percoco, Rapid Prototyping J ournal, (2015)

11. M. M ohammadizadeh, A. Imeri, I. Fidan, M. Elkelany, Composites Part B, vol. 175, (2019) 